\title{
'An investigation of cultural influence on academic library usage and experience of international medical students from Asian countries: a case study of students at the Christchurch School of Medicine, University of Otago, Christchurch.'
}

\section{by}

\section{Thanawadee Pibulsilp}

\author{
Submitted to the School of Information Management, \\ Victoria University of Wellington \\ in partial fulfilment of the requirements for the degree of \\ Master of Library and Information Studies
}




\section{Acknowledgements}

First, I am very grateful to my supervisor Brenda Chawner, senior lecturer at the School of Information Management, for her tremendous help and support throughout the whole process of this research project. Her guidance played a big part in the accomplishment of this project.

Furthermore, I am indebted to Marg Walker, Chief Librarian, Carol Davison, Deputy Librarian, and every staff member at Canterbury Medical Library, especially Patricia Burnett and Natasha Graham for enabling me to have this project underway and completed. I also would like to extend my thanks to Ruth Helms and Carol Milnes from Medical Education Unit for granting the permission for and mediating the interview process.

I am grateful and privileged for the dedicated time and effort of all participants at Christchurch School of Medicine, University of Otago, Christchurch. The research could not be completed without their contribution.

There are many individuals and families who I need to mention. 
Thank you Creon Upton for showing me the light at the end of the tunnel. You gave me chances, challenges, and a sense of confidence in everything I do. The path to success seems to be much less a stumbling block when I work alongside you.

To my parents, my sister and two little nephews thank you for being patient and great listeners. Their long distant loving and caring support were always there when I needed it the most. To my Satriwit and Silapakorn friends in Thailand, as well as Por, my dear friend in New Zealand, who always send their compassionate messages and unshakable friendship, thanks.

To the Stewart family, especially Benjamin, who has made me realise my hidden strength and Cathy who has always taken care of me with love and tenderness.

Without the assistance and support of those mentioned above, I could not have completed this project. 


\section{Contents}

Acknowledgement

Contents

Abstract

CHAPTER 1 Introduction 1

CHAPTER 2 Problem statement 2

CHAPTER 3 Literature review 5

$\begin{array}{lr}\text { CHAPTER } 4 \text { Research objectives } & 18\end{array}$

CHAPTER 5 Research methodology 23

CHAPTER 6 Findings $\quad 31$

CHAPTER 7 Discussion and recommendations 43

CHAPTER 8 Conclusion $\quad 55$

$\begin{array}{lr}\text { Bibliography } & 57\end{array}$

Appendixes

Appendix 1: Information Sheet

Appendix 2: Student Consent Form

Appendix 3: Technical Assistant Non-disclosure Agreement

Appendix 4: Interview Schedules 


\section{Abstract}

This research uses a qualitative methodology to analyse the academic library usage and experiences of International Medical (IM) students from an Asian cultural background studying medicine at the Christchurch School of Medicine, University of Otago, Christchurch, New Zealand. There has been little research done investigating the library experiences of students from other cultures, despite international evidence that usage habits and experiences of these cohorts can differ greatly from those of local students. With increasing numbers of students from other cultures studying in New Zealand, it seemed that data should be gathered to inform the development of library services. Fifteen $4^{\text {th }}$ and $5^{\text {th }}$ year students from culturally Asian backgrounds participated in focus groups using semi-structured interviews, and transcripts of these interviews were analysed using narrative and discourse analysis. The findings support the work of Hofstede and indicate that an Asian cultural background has a significant impact on students' knowledge of, and ability to utilise, academic library services; however, it is also evident that such knowledge and ability is eventually acquired by students through their friendship groups, but this is often in an ad-hoc manner. It is recommended that academic libraries develop greater awareness of the impact that cultural background can have on the library usage and experience of the increasing numbers of students from foreign cultural backgrounds in New Zealand medical settings in particular, and academic settings in general. 


\section{Key words:}

Academic libraries; library services; international students; medical students; New

\section{Zealand}




\section{CHAPTER 1}

\section{Introduction}

New Zealand and many other developed countries around the world are increasingly facing the impact of cultural diversity. Especially in the late twentieth and early twentyfirst centuries, there have been constant flows of immigrants from their homelands to new countries, either to work, study, or live. New Zealand is currently one of the countries that have the highest number of immigrants in the world (Singham, 2006). New Zealand has been a popular destination throughout this time, and it has inevitably become one of the many culturally diverse countries. New Zealand is also a temporary residence for many expatriates and international students. This movement to a wider mixed-race population has affected the emergence of spoken languages other than English and Maori. There is now a large population who does not speak English as a first language. The 2006 Census by Statistics New Zealand showed that of the major ethnic groups, the Asian ethnic group grew the fastest between 2001 and 2006, increasing from 238,176 people in 2001 to 354,552 people in 2006, an almost 50 percent increase. The Government's responses to ethnic diversity have raised awareness of cultural and linguistic differences in communities, in workplaces, in education, and in government agencies such as hospitals and libraries. Libraries, as agencies that represent a recreational and educational hub for people in the community, have a responsibility to meet the needs of the multicultural communities they serve. This brings up many questions in library practices. What is cultural diversity in libraries? How does it concern libraries? And what needs to be done to library services in response to this cultural diversity? 


\section{CHAPTER 2}

\section{Problem statement}

University is viewed as one of many places where a distinct mixture of students from different cultures and ethnicities coexist. Students from a culturally Asian background now make up a substantial proportion of the New Zealand tertiary student body. According to Deloitte (2008) there were nearly 40,000 international enrolments in New Zealand tertiary institutions in 2001. This figure rose to approximately 60,000 by 2006 . The increasing numbers of Asian international and immigrant students in New Zealand tertiary institutions have prompted many New Zealand academic librarians to rethink their assumptions about who their library users are. Coates, Hiyama and Wellington (2004) report the evidence of growing numbers of students who identify themselves as being of 'Asian' ethnicity. Understanding the library experiences and library usage of these students from their culturally specific point of view is the problem this research addresses.

There is considerable published international literature that discusses many aspects of international students and academic libraries. This literature is largely American. There is also a small amount of research done on New Zealand specifically. To mention a few: Coates et al. (2004), Mu (2007), Uchibayashi (2000) and Wang (2006); their findings are similar to those in international library literature (Badke, 2002; Curry and Copeman, 2005; Jackson, 2005; Liu and Redfern, 1997; Sackers, Secomb and Hulett, 2008). Many of these dominant issues are language barriers, inter-cultural communication, unfamiliar library systems, different learning styles and approaches, and cultural differences. New 
Zealand studies also explore these issues faced by international students. Several of these chiefly examine various library services to international students from different faculties, especially Chinese students in major cities like Auckland (Coates et al., 2004) and Wellington (Wang, 2006). However, New Zealand library and information studies research does not show much interest in investigating academic library members in specific disciplinary areas, especially medicine and health sciences. New Zealand standard undergraduate degrees in faculties such as Humanities or Commerce take three years to complete whereas medical degrees take six years. Medical students, like other students, spend their years 1 to 3 , also called pre-clinical training, in attending lectures, doing their course work, and sitting their examinations, but they have another three more years before their graduation.

These last three years are called clinical training where their way of learning is organised as clinical placement learning from clinical lecturers as well as other health care providers in hospital departments rather than lectures learning from one lecturer within university walls. Moreover, the practice of evidence-based medicine (EBM), which requires the best current evidence used in decision making about patient care, is introduced to these students in their clinical years. Clinical training years for medical students are demanding on students' time, medical knowledge, and medical and library skills. They need to be highly motivated, well organised and self-reliant for themselves. Moreover they are required to be good communicators, well informed, and good at decision making for applying their knowledge to patient care. All of these skills also apply to international medical (IM) students from different culture, particularly in their teaching - learning philosophy. This poses an important question to academic librarians 
about how librarians can the best help IM students to successfully face the demanding challenge of transition to new teaching environment and new learning approach to succeed in their clinical training and be well equipped with a new library skill set.

International students from all disciplines may face many of the same issues, such as language and cultural barriers and lacking knowledge about library services, when they adjust to the unfamiliar system of New Zealand academic libraries. IM students in New Zealand have not yet been studied to see if their cultures have any influence on how they use and experience the academic library services and what academic medical librarian can provide library services that suit the needs of this specific group with unusual teaching-learning methods, a mobile learning off-site and sometimes in other part of the country or the world, which is a necessary part of their clinical training in the school of medicine. Using as a case study medical students of a culturally Asian background at the University of Otago, Christchurch School of Medicine (CSM), this research aims to investigate how Asian cultural background influences the use and experience of academic library services in New Zealand. 


\section{CHAPTER 3}

\section{Literature review}

There are two medical schools in New Zealand: the University of Auckland and the University of Otago. New Zealand government annually funds around 110 places for the University of Auckland and 170 places for the University of Otago. Both universities are allowed to provide a small number of places to full-fee paying international students. The duration of medical training is six years, which is divided into two phrases: pre-clinical years $\left(1^{\text {st }}, 2\right.$ nd, $3^{\text {rd }}$ years $)$ and clinical years $\left(4^{\text {th }}, 5^{\text {th }}, 6^{\text {th }}\right.$ years $)$. Medical students at the University of Otago attend their pre-clinical years in Dunedin and then can choose to attend one of three medical schools: Dunedin School of Medicine (DSM), Christchurch School of Medicine (CSM), and Wellington School of Medicine (WSM), to complete their clinical training years (Fitzjohn, Wilkinson, Gill, and Muldar, 2003). There are also international medical students from overseas partner universities such as International Medical University in Malaysia who can choose to attend their last three clinical years at Christchurch or Wellington School of Medicine (IMU, n.d.). There is a substantial number of IM students from Asian countries enrolled at CSM each year. In 2009 there are 46 Asian IM students from the total of 245 medical students at CSM. Malaysian IM students take the largest portion of places, followed by Brunei and Singapore then China and South Korea. This confirms the international student enrolments 2001-2007 report from the Ministry of Education of increasing numbers of Asian international students in the tertiary sector from 20,405 in 2001 to 31,143 in 2007 in New Zealand, when there were 1,658 Malaysians enrolled in universities (Ministry of Education, 2008). The rise of 
cultural diversity in medical education has caught the attention of academic medical librarians and medical schools around the world. The majority of these literatures are from United Kingdom and Australia. They emphasis the impact of medical students from other cultures in relation to challenges and barriers in teaching foreign students and learning difficulties and academic adjustment issues especially ones of Asian origin (Klimidis, Minas, Stuart, and Hayes, 1997; Woolf, Cave, Greenhalgh, and Dacre, 2008; Lempp, and Seale, 2006). This phenomenon unavoidably receives attention from library and information studies research. The majority of research done on medical students and academic libraries generally concentrates on library use, information needs, and information seeking behaviours (Ajayi, 2004; Adedibu and Adio, 1997; Eskola, 1998). Their findings confirm similar issues faced by international students from other academic disciplines, only different in their preferred sources of information searching, which is evidence-based medicine database searching rather than textbooks.

To understand issues of cultural diversity in academic libraries is to understand what constitutes cultural diversity in wider society. There are many definitions. However, there seems to be a common thread among those differences. Du Mont et al. (1994) suggest that cultural diversity refers to a sensitive recognition of existing cultural differences. They cite a definition developed by the National Coalition for Cultural Pluralism:

Thus, it is a state of equal co-existence in a mutually supportive relationship within the boundaries or framework of one nation of people of diverse cultures with significantly different patterns of belief, behavior, color, and in many cases with different languages. To achieve cultural pluralism, there must be unity with 
diversity. Each person must be aware of and secure in his own identity, and be willing to extend to others the same respect and rights that he expects to enjoy himself.

There are also other authors who suggest that technology and globalisation affect multiculturalism. Skrzeszewski (1998) explains that multiculturalism traditionally focuses on minorities in one country. These minorities are often refugees and/or immigrants. The focus of cultural diversity in the twenty-first century has included not only minorities within one country, but also cultural groups within a global society. De Ruijter (1997) supports this concept, arguing that in effect the world is getting smaller. Advanced technology is turning the world into a global village, and people from all societies are faced with aspects of societal and cultural diversity. Cultural diversity in academic libraries should recognise the different cultures or cultural identities within that society to promote social cohesion within a context where no one culture or worldview is seen as predominating.

\section{Multicultural issues in academic libraries}

The increasing numbers of international and immigrant students in New Zealand tertiary institutions means that many New Zealand academic librarians are rethinking their assumptions about their patrons' cultural identities and the impacts of these on their library experience. This is particularly the case with the increasing numbers of culturally Asian students. Du Mont et al. (1994) explain that the same trend happened in America. The American universities' libraries tried to meet the needs of a wide range of minorities, ethnic groups, as well as international students from around the globe. Multiculturalism 
in the context of universities covers various subcultures, new immigrants, and overseas students. Universities have become small communities that need to find constructive and innovative ways to integrate cultural diversity (Reece, 2005). A great deal of published literature from America includes minorities, ethnic groups, and international students as multicultural library users, whilst New Zealand studies tend to concentrate only on either minorities or international students. By comparing these few example pieces of research, by Du Mont et al. (1994), Curry \& Copeman (2005), and Coates et al. (2004), it is clear that their findings show similar issues or barriers among culturally diverse users, minorities, immigrants, and international students. These issues or barriers can be broadly discussed in terms of three essential problems: language, cultural barriers, and awareness of library services.

\section{Language}

Both international and minority students often experience a language barrier. Du Mont et al. (1994) refer to Asian Americans, Hispanic Americans, and international students as having language difficulties and responding more to a librarian who can speak their native language. Curry and Copeman (2005) also find that the language barrier is a major issue impacting on the library experience of multicultural users. It may result from international students' inability to express their needs correctly, as well as from librarians' inabilities to understand students' pronunciation, intonation, speech patterns, and enunciation. These barriers are confirmed by Coates et al. (2004), who argue that library information should be available in both English and alternative languages. They also suggest that bilingual librarians should be easily identified and accessed by international students and minority users. 


\section{Cultural barriers}

African Americans and Native Americans do not seem to experience significant cultural barriers. However, many newly migrated Asian Americans and Hispanic Americans face the problem of conforming to the new culture (Du Mont et al. 1994). International students also face this situation. In particular, their different learning styles, information needs, and information seeking behaviours may hold them back when communicating with librarians (Curry \& Copeman, 2005). Coates et al.'s conclusion is further consistent with the other two studies. They find that Asian students like to gather information from their friends rather than from librarians or other information specialists: they are shamed and embarrassed when they have to ask for help. Asian learning styles are based on observation rather than participation, and these students are often intimidated by the expectations that they actively seek advice.

\section{Awareness of Library Services}

These three studies, and many multicultural researchers, have the same opinion on this issue. Library users, especially those from Asia, are not familiar with librarians' roles. They are not aware of common library services, such as open stacks, interlibrary loans, or online services. Classification systems and subject headings are unknown concepts, which may not exist in their home countries. These factors suggest the importance of understanding the cultural backgrounds and established information-gathering practices of multicultural users within the academic library context. It further challenges librarians' basic assumptions about the normality of their professional practice.

\section{Planning for diversity}


There are vast amounts of published literature about cultural diversity in libraries, from New Zealand and other countries, especially America, Canada, and Australia. They all give similar advice and suggest similar practical solutions. Raising awareness and showing a commitment to playing a leading role in serving a linguistically and culturally diverse community is clearly displayed, not only to library staff but to all university staff and students, as well as communities outside the university. Du Mont et al. (1994) suggest mission statements. They say that academic libraries can respond to diversity by planning and programming and by addressing cultural diversity in their mission statements. Academic librarians should work to overcome multicultural students' issues and barriers. Library managers can help their staff by organizing cultural diversity workshops or providing library staff development and training programmes. Much of the literature suggests that academic libraries can raise the visibility of librarians for international students by having a diversity librarian position or the equivalent.

Cultural difference is an important reality in many developed countries. The world will become smaller with the help of advanced technologies. It is inevitable that communities will exchange and communicate their knowledge, beliefs, culture, values, or heritage. Academic libraries, as part of the education community, are also experiencing this phenomenon. It is no longer practical to rely on traditional library services that do not accommodate multicultural library users, but consider only dominant groups of users such as European New Zealanders in New Zealand libraries. The mission of New Zealand academic libraries should be not only to meet the information needs and expectations of certain predominant groups of users, but should take an inclusive approach by reaching out to other minor groups of students, such as students of other 
ethnicities. However, it is not easy to accommodate all the needs of all culturally diverse users. These libraries need to do their own research into who their users are, and what information needs they have. They need to consider whether there is any barrier or issues not yet identified. These libraries need to find appropriate methods to obtain this information. These collected data can then be used to improve or develop library services that are tailored to their culturally diverse communities

\section{Theoretical Framework}

The theoretical framework for this research is based on the "cultural dimensions" identified by sociologist Geert Hofstede in the context of the information behaviour of medical students in New Zealand of a culturally Asian background. Hofstede's comparative study of IBM employees' work-related values in the 1970s resulted in the publication of his book "Culture's Consequences" in 1980 (Hofstede \& Hofstede, 2005, p. ix). The book presents four dimensions of national culture and provides a framework for cultural analysis. This book has drawn much attention at the academic level. It has become one of the most read and cited sources in cultural-social research (Drenth, 2004, p.1; Dahl, 2004). Hofstede and Hofstede (2005, p. 23) explain the term dimension as "an aspect of a culture that can be measured relative to another culture". Hofstede defines culture as the collective programming of the mind which distinguishes one group from another. Elements of culture display in internal values, which are invisible, and practices, which are visible. Values, as the core of culture, are "a broad tendency to prefer certain states of affairs over others". Values are revealed through practices which include rituals (collective activities), heroes (respectable persons), and symbols (words and gestures). 
According to Hofstede (2005) every group of people carries a set of common mental programmes which comprise its culture. Differences between two organisational cultures are distinguished by their practices or common behaviours whereas differences between two national cultures are characterised by their values. Values and practices are acquired early in our lives and from our environment such as family, school and work.

Consequently it is complex and problematical to change them later in our lives especially when facing another national culture. Hofstede's research presents the national culture in four dimensions. These four dimensions are Power Distance (PDI), Uncertainty Avoidance (UAI), Individualism versus Collectivism (IDV), and Masculinity versus Femininity (MAS). In his later edition of Cultures and Organisations: Software of the Mind Hofstede added the fifth dimension: Long and Short-Term Oriented (LTO), which, however, is not suitable to use in this research because he did not measure a score for Malaysia. Eighty percent of participants in this research are from Malaysia, and it is thus not possible to use his fifth dimension to analyse these participants.

\section{Power distance}

Hofstede (2001) defined power distance as "the extent to which the less powerful members of institutions and organizations within a country expect and accept that power is distributed unequally". In a small power distance country such as New Zealand, which scored 22, equality is important. Organisations are more likely to be decentralised. Superiors and subordinates rely on each other as supports. In educational situations, New Zealand students have an equal student-teacher role pair and expect to be treated as equals. Student-centred is the preferable approach in education. Teachers encourage 
students to be independent thinkers. The educational process is impersonal and teachers only transfer facts or truths which can be questioned if students do not comprehend (Hofstede et al, 2005, p.54). On the contrary, subordinates expect to rely on their superiors in a larger power distance country. Inequality is expected. Large differentials in salary or status symbols are evident. Students from large power distance countries show great respect to teachers inside and outside school. The inequality of the teacher-student role pair is evident. The teaching method is teacher-centred and highly personalized. Teachers transfer personal wisdom to dependent students with strict orders that this be followed and never criticized (Hofstede et al, 2005, p. 53).

\section{Uncertainty avoidance}

The second dimension is described as "the extent to which members of a culture feel threatened by uncertain or unknown situations" (Hofstede, 2001, p. 161). Countries with high uncertainty avoidance scores usually need strict rules to prevent or minimise uncertainties in the society. Citizens of such a society have a need for a structure to reduce fear or anxiety created by ambiguity. The same rules apply in school where strict timetables, highly structured curricula, detailed objectives, and descriptive coursework are preferable. Teachers are expected to know all the answers and students are concerned to find one correct answer. On the other hand, countries with low uncertainty avoidance do not regard ambiguity or uncertainty as a threat or dangerous. Students have more freedom in their learning approach. They are pushed to be innovative and are rewarded for their creativity. Teachers are not expected to give all correct answers. Debates or disagreement in classes are regarded as positive learning methods and are promoted. 
Students prefer limited timetables, wide-range learning objectives, and open choices for assignments (Hofstede et al, 2005, p.178-179).

\section{Individualism versus Collectivism}

Individualism is related to a society in which the ties between individuals are loose: everyone is expected to look after himself or herself and his/her immediate family only. Collectivism is related to a society in which people from birth onwards are integrated into strong cohesive in-groups, which throughout people's lifetime continue to protect them in exchange for unquestioning loyalty (Hofstede, 2001, p. 225). In countries with high individualism scores such as Great Britain or New Zealand an individual is not under pressure to belong to any group. Language is used to express one's opinion and does not represent other than oneself. Children are encouraged to speak their minds and be selfreliant. When they are at school the same practices are reinforced. Students are seen as individuals regardless of their backgrounds. Teachers encourage open discussion and make sure students know "how to learn" (Hofstede et al, 2005, p. 98). By contrast, in a collectivist society everyone belongs to a group. There are certain expectations of a person in a group to be loyal and responsible for the group's social image and well-being. Children in a collective society learn to use words like "we", such as in Japan or China. They must think carefully about their expression and action as they need to protect and maintain the group social image and responsibility. In school teachers treat a student as part of an inclusive group. Harmony is promoted in the classroom, with the least possible conflicts or confrontation. It is commonly acceptable for students and parents to expect 
special treatment from teachers or other school personnel on the basis of coming from the same ethnicity or family background (Hofstede et al, 2005, p. 98).

\section{Masculinity versus Femininity}

Hofstede (2001) explains that masculinity stands for a society in which social gender roles are clearly distinct: men are supposed be assertive, tough, and focused on material success; women are supposed to be modest, tender, and concerned with quality of life. Men are judged by their material success and career advancement, but women are expected to be caring and modest. Their roles in society are very distinctive. Like in New Zealand, students from a masculine culture are openly competitive with each others. Good students get praise when they excel but not easily forgiven when fail at school (Hofstede et al, 2005, p. 137). Femininity stands for a society in which social gender roles overlap: both men and women are supposed to be modest, tender, and concerned with quality of life. In a feminine society men's and women's roles are not separated. The society is more concerned about quality of life, relationships and social performance. In school, children are friendly and modest. Aggression and overt competitiveness in academic excellence are not promoted. Teachers' attention and praise are usually for weak students and failure in school is not a tragedy.

Hofstede's cultural dimensions framework is applied when the data is analysed to compare the findings of this research with Hofstede's findings and discover possible parallels. 
Figure 3.1 Comparison of Hofstede's four cultural dimensions*

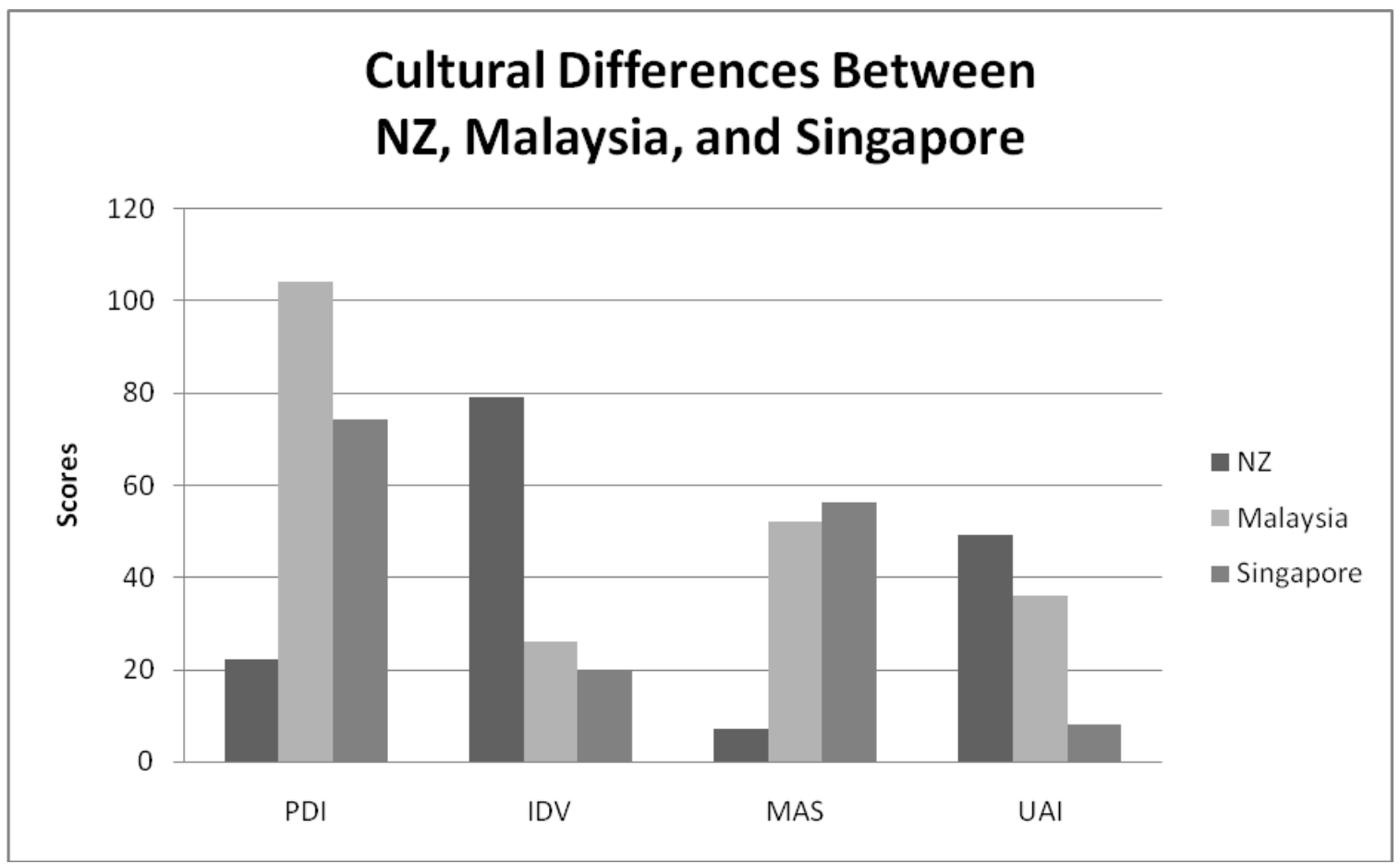

Source: Hofstede and Hofstede (2005)

*Brunei is not shown here because there is no score collected

\section{Research gap}

This research investigates how Asian cultural background influences the use and experience of academic medical library services in New Zealand. Twenty participants are recruited from the $4^{\text {th }}$ and $5^{\text {th }}$ year international medical students from Asian countries at the University of Otago, Christchurch School of Medicine. The reasons this research study medical students rather than students who enrol in other disciplines are the demanding and unique nature of medical study, these students' longer exposure to the academic library's services, and the lack of previous study of this particular group in New 
Zealand. There has been no research conducted specifically on international, Asian medical students in New Zealand, yet they need to use the library services for longer and more complex purposed than other students on the campus. New Zealand medical training is a six year degree. The medical students at University of Otago must spend their $1^{\text {st }}, 2^{\text {nd }}$, and $3^{\text {rd }}$ year, also called pre-clinical study, at the Dunedin campus and then choose to be trained at one of the three University of Otago medical schools (Dunedin School of Medicine, Wellington School of Medicine, and Christchurch School of Medicine) for their final three years, also known as clinical study. However, there is an exception for some international students, who are on overseas scholarships or are funded by their own government to study at the University of Otago for only their final three years. Their pre-clinical years are organised in a similar way to other science degrees, with lectures, coursework, and examinations. However their $4^{\text {th }}$ to $6^{\text {th }}$ years are for clinical training in hospital setting. They are expected to spend the majority of their time acquiring clinical skills and knowledge. Evidence-based medicine (EBM) is also introduced in their clinical year and will be further used in their medical career. EBM is the use of current best evidence in decision making for patient care. It is a combination of clinical expertise and the external clinical evidence from systematic research (Sackett, D. L. et al, 1996). IM students must be equipped with skills of selecting appropriate resources, conducting the best search and appraising the reliability of results. These skills are vital to the IM students' academic and career achievement, yet there is not enough evidence or library research done on what issues these IM students face in their clinical year, especially when they come from different cultures and learning backgrounds from New Zealand students. 


\section{CHAPTER 4}

\section{Research Objectives}

The research sets its sights on an investigation of cultural influence on academic library usage and experience of international medical students from Asian countries by selecting a case study of students at the Christchurch School of Medicine, University of Otago, Christchurch. The objectives of this research are:

1. To learn whether (and in what ways) a culturally Asian background influences perceptions of library services among student library users of that background at the University of Otago, Christchurch School of Medicine.

2. To learn what library services those students commonly use and do not use, and to determine whether those behaviours are influenced by their experience of difference between New Zealand libraries and libraries in their countries of origin.

3. To suggest ways in which libraries may respond positively to changing cultural demographics among their users, especially in respect to users from a culturally Asian background.

\section{Research Questions to be investigated}

1. What kind of library services do students of a culturally Asian background use and not use? 
2. What are this minority group of students' experiences of New Zealand academic libraries?

3. What are the differences between the library services in New Zealand and in the students' home country?

4. What are barriers in the library services? Are these barriers culturally influenced?

5. What do academic libraries need to do to improve the use and experience of students of a culturally Asian background?

\section{Definition of terms}

"International student", according to New Zealand Ministry of Education, means a person who:

(a) is enrolled by a provider; and

(b) in relation to the provider, is a foreign student as defined in section 2 or section 159 of the Act (whichever is applicable).

International students commonly are full-fee or foreign fee paying (FFP) students in New Zealand. In some cases, international medical (IM) students are funded by their government or with overseas university who has an agreement with University of Otago to provide placements in their $4^{\text {th }}, 5^{\text {th }}$ and $6^{\text {th }}$ year clinical training. International Medical University in Malaysia is one of the major partner universities who send their students to Christchurch or Wellington campus. 
"Library services" for this project include library opening hours; lending desk; reference desk; student reserve; library catalogue; library orientation; library instructions and training; interlibrary loan; borrow direct; and print and electronic collections.

\section{Purpose of the study}

Currently there is very little knowledge or understanding of the experiences and use of academic libraries by international medical students from Asian countries within the New Zealand tertiary context. The need for this kind of study is becoming increasingly apparent with increasing numbers of international students in New Zealand tertiary institutions. This group of international students spends twice as much time as students from other disciplines as library users. They unavoidably continue using library resources from the beginning of their professional year. Medical academic librarians have to ask themselves what their perception is of this particular group of students and how they can respond to their needs, which may be different from local students. Medical students in particular need to be equipped with the most up-to-date, accurate and reliable information, and they must know the channels to get to this information. Medical libraries have always been where medical students learn to hone their information gathering skills. Any obstacles preventing these medical students from becoming competent information searchers may jeopardise their success in their medical training and later in their career, possibly affecting their patients' well-being. Coming from a different culture can have a great effect on international medical students' potential in becoming proficient library users. 
There is considerable published international and New Zealand literature that discusses many issues faced by international students from Asian countries while adjusting to new library systems and different services in libraries outside their own countries. Culture is one of the main issues which shape how this student demographic view and utilise the library and its services. International medical students may not reap the full benefit from various library services provided, unlike their local peers, because of cultural beliefs and practices which may impede them. For example, Asian students generally tend to stay in a closely tied group of friends, gather information from their friends, and only speak up when nominated to by the group. According to Geert Hofstede (2005) this is typical behaviour of students from a collective culture, and most Asian countries are collectivist. New Zealand, on the other hand, has a high degree of individualism in its culture. International students are likely to come to library training in a group, prefer to consult their friends not the librarian when they do not understand, and when one speaks it usually represents the whole group. This kind of behaviour, if not fully understood by the librarian, is likely to be misinterpreted, giving a mistaken impression. This may later cause the librarian to be frustrated and reluctant to provide services to this type to student.

This research is intended to investigate how much cultural background influences the library usage and experience of international medical students from Asian countries. The results could potentially benefit both academic libraries and international medical students. Academic libraries should be able to gain an insight into how much culture influences international medical students' behaviour, to utilise these research finding to have a better understanding of cultural complexity, to discover unidentified issues and 
solutions for improving the use and experiences of library services, and to provide an adequate multicultural environment for this minority group of students. As a result, the many issues that face international medical students within a foreign learning environment can be decreased to some extent, providing library users with an environment that is sensitive to their unique needs.

International medical students' behaviour and practice, at the same time, will be more fully understood, meaning that cultural barriers, which could prevent them from gaining information required for their study, will be reduced. Their information needs can be appropriately met and services carefully tailored to accommodate them. As a consequence, these students should be enabled to take advantage of library services to their full potential, become well-informed library users, and improve their academic performance, information gathering aptitude, and medical careers. 


\section{CHAPTER 5}

\section{Research Methodology}

The methodology for this research is qualitative research through interviews with focus groups using semi-structured questionnaires. Qualitative research is appropriate for the interpretivist paradigm that is being used in this study. It allows us to gather information through dialogue within the context in which events occur (Gorman and Clayton, 2005, p. 4), providing discursive data that can be thoroughly analysed to help us understand the nuances of the opinions expressed. This is opposed to quantitative data gathering, which finds numeric data of a high level of precision but without the subtleties of human feelings and experience. These feelings and experiences are reflected in qualitative research methodologies because they focus on the interactive expressions of individuals expressing themselves through their own discourse. Gorman and Clayton (2005) suggest that to the narratives that the subjects tell, "the researcher, having entered the context personally, can add observations about physical aspects of behaviour, descriptions of settings, and other characteristics of the environment" (p. 5).

The use of a qualitative methodology using focus groups and semi-structured questionnaires involves organised discussion with a group of individuals from the subject category of the research to gather information about their ideas and experiences of the area being researched. This research specifically finds the feelings and opinions of the population being studied. These feelings and opinions need to be understood through this contextual based research where the subjects are able to express their experiences through narrative and group dynamics, offering the researcher insights into the emotional and 
"deep" aspects of their experiences. This reflects the overall group feelings that apply to the topic of library use in the New Zealand tertiary context, and provides more useful information than from data from a questionnaire used in quantitative research.

It was decided to use focus groups rather than other methods, such as observation, which can be very time consuming, and where the subject tends to behave differently when being observed. Moreover it is not always possible to foresee an unplanned event and be prepared to observe such an event (Gorman \& Clayton, 2005). One-on-one interviews are ideal if the sampling population is small; they are not feasible in terms of the population size and time constraints of this particular research. The focus group setting, given the external constraints of the research, provides useful data from a cross-section of IM students of a culturally Asian background in New Zealand tertiary education. Focus groups can be very pleasant and interesting experiences for sample populations like these IM students because of their tendency to act as a group. This also reduces the time spent on the interview process and eases reluctant participants into sharing experiences and thoughts. Focus groups can provide very similar information to one-on-one interviews and give the interviewer an opportunity to observe an interaction within the group. For these reasons, and because they are more convenient for this research, they are chosen. On the other hand, surveys, whether online or send-out, are not immediate in their responses and have unreliable return rates.

The data I obtain from the focus group interview allows me to provide answers as to whether IM students' personal experiences of using an academic medical library in New Zealand are influenced by their Asian cultural background. Because the idea of 
cultural background is complex, the focus group approach gives these IM students the opportunity to reflect on their experiences with their peers and discover attitudes that might not be obvious to them individually.

\section{Population}

This research investigates how Asian cultural background influences the use and experience of academic medical library services in New Zealand. The participants are recruited from the $4^{\text {th }}$ and $5^{\text {th }}$ year international medical students from a culturally Asian background at the University of Otago, Christchurch School of Medicine in the 2009 academic year. The Academic Programme manager at CSM provided the list of IM students from Asian countries. These IM students must spend their pre-clinical years, which are first to third academic year, either at Dunedin School of Medicine or overseas medical schools in Asia. They should have been studying Christchurch School of medicine and using Canterbury medical Library for at least one semester. These IM students have been living in New Zealand for duration of six months to four and a half

years. There are 18 and $15 \mathrm{IM}$ students enrolled in $4^{\text {th }}$ and $5^{\text {th }}$ year respectively in 2009. Electronic mail invitations were sent to all 33 IM students containing detail of the project and asking them to reply directly to the researcher. The research had a limit of 20 participants. The first $20 \mathrm{IM}$ students who responded to the invitation were accepted and later self-selected to attend one of four focus group interviews according to their time availability. 


\section{Pilot study}

Three $6^{\text {th }}$ year international medical students accepted to be interview as a pilot session of semi-structured open ended questions. The interviews took approximately 45 minutes. The session was not audio recorded but students' responses and comments were noted by the researcher. These three IM students had a good command of the English language and were comfortable in exchanging ideas. They understood almost all pre-written questions but did not understand or never knew some library terms, such as OPAC, Borrow Direct and the likes. These are the library terms that the researcher suspected are not common amongst medical students and expected a need for explanation from students. These terms were kept the same and it was noted that they should not take too much time in explanation. Another point, which the research took note of and after the pilot session altered the question slightly, was questions that led students to accept the researcher's term rather than their own words, or limited their responses. These questions were usually used as follow up for more details from students. For example, leading questions like "so what was the service like for you?" or "was it acceptable?" only received limited answers, for example "it was ok for me" or "yes it's acceptable". The researcher made note of this and changed the questions to more opened ended, such as "what was the service like for you from your previous experience? Would you like tell us about it?"

\section{Method of data collection}

For this research a semi-structured questionnaire using open-ended questions was designed to gather responses that answer to the research questions of the study. The questionnaire was piloted and adjusted because there were some concerns about wording 
and leading questions before the interview. This was used for focus group interviews, which is appropriate to the population that the research focuses on because this provides different perspectives on the same issues faced by members of the target population. This seems to work well with people from other cultures because participants are likely to enjoy talking in pairs or small groups, helping each other to understand the topic and finding ways to approach it (Gibbs, 1997). Also, according to Gorman and Clayton (2005), focus groups have the advantage of showing the interactions between the participants and they are likely to express more personal experiences that come up unexpectedly rather than being prompted by the question. This gives insight into how the subjects approach the topic, rather than this being imposed by the researcher.

The focus group interviews were organised through the Medical Education Unit at the Christchurch School of Medicine. The academic programme manager granted permission to contact IM students for the interviews. The Undergraduate Administrator provided the list of IM students from Asian countries. There were 18 and 15 IM students enrolled in $4^{\text {th }}$ and $5^{\text {th }}$ year respectively in 2009 . Electronic mail invitations were sent to all 33 IM students containing details of the project and asking them to reply directly to the researcher. The research had a limit of 20 participants. The first 20 IM students who responded to the invitation were accepted and later self-selected to attend one of four focus group interviews according to their time availability.

The email invitation explained the project's aim, method and the scope of only 20 participants. It also asked students to choose one slot of time (out of four available) that they were available for the interview. The students were asked to send their replies to the 
researcher. The 20 participants were automatically divided into four groups according to their time availability as indicated by the students to be interviewed. The groups were randomly organised and not chosen based on nationality or cultural background.

There were two interviews per week, with the pre-determined semi-structured questionnaire being used to guide discussion. Each interview took 1-1.5 hours. The questions had been piloted to test their reliability. The interviews were conducted in a university lecture room to provide the students with a familiar environment. The interviews were recorded using audio recording with help from a technical assistant and later transcribed by the researcher. The researcher also took notes during the interview and after it has been concluded. The sessions began with an introduction of the research and its aims, explaining that the questions had been tested and that they are set questions but that participants are encouraged to express themselves about any concerns or ideas they have outside the questionnaire. Thus, any question or topic that had not been covered could be introduced. The researcher then reviewed the student consent form with the participants and if the participants were happy to continue, the forms were signed. Each participant received a consent form to sign and return to the researcher, and an information sheet about the project scope to keep. It was explained to the students that the interviews were private and confidential, and that the results would not be published or disseminated in any form outside the fulfilment of the research itself.

\section{Data analysis techniques}

In the focus group interviewing sessions the researcher, with help from a technical assistant, recorded the sessions using an audio recorder, as well as taking notes about the 
actions of the participants during and after the sessions. The recorded interviews were then transcribed by the researcher with reference to their notes. Rather than paying a professional typist to transcribe the interviews, the researcher personally transcribed each interview. This process is important for confidentiality and privacy of the participants and allows the researcher to look carefully at the participants' contributions and notice elements that they may have missed in their note-taking. The transcription is performed as soon as the session is finished, and the notes are expanded based on this information.

The information is analysed using open coding techniques, which identify recurrent themes, ideas, words, or phrases that appear throughout the interviews or in the researcher's notes. These need to be interrogated to assess the particular biases or points of view that they reflect, and they can subsequently be categorised and sub-categorised according to their common features. These categories of information provide the basis for the development of a conceptual understanding of the issues that relate to the research questions. The encoding forms the basis for the findings of the research.

Another consideration in the data analysis is narrative and discourse analysis (Pickard 2007), which is the study of how the subjects construct meaning and understanding through the development of narrative story-lines through which they make sense of their experiences. Recurrent themes, ideas and interpretations are borne out through the narrative process, shedding light for the researcher on the form of meaning and comprehension that the subjects bring to their experiences. The real experience is transformed into an account that can be shared and communicated with others, illustrating the extent to which meaning is constructed as a shared and communal way of understanding events in the world. By harnessing this epistemology, the researcher is able 
to uncover, through the focus-group dialogues, the significant structures of interpretation that the subjects use to make sense of their experiences.

\section{Limitations}

There are only two universities, namely University of Auckland and University of Otago, offering medical degrees in New Zealand. The University of Auckland has one medical school and The University of Otago has three medical schools. To get the whole picture of how Asian cultural background influences the use and experience of medical students' academic library services in New Zealand is to do nationwide research at all four medical schools. However, this research is limited to a case study of international medical students of a culturally Asian background at the University of Otago, Christchurch School of Medicine for two reasons. The time constraint is the first major obstacle. The researcher has an obligation to complete the research project with two academic trimesters. The focus group interview, the chosen method, takes considerable time to conduct and analyse the collected data. This leads to the second reason. To be able to work within the timeframe, this research has limited participants to 20 medical students from $4^{\text {th }}$ and $5^{\text {th }}$ year. The $6^{\text {th }}$ year medical students were not invited because of their exhaustive medical training as trainee interns in the hospital departments. There is a possibility that the $6^{\text {th }}$ year students will not have enough time to be interviewed, and this may jeopardise the whole project. 


\section{CHAPTER 6}

\section{Findings and Discussion}

Invitation emails were sent to 33 IM Asian students from $4^{\text {th }}$ and $5^{\text {th }}$ year. Sixteen IM students responded to participate in the focus group interviews. One student missed out and 15 students were able to attend the interviews. Four focus group interviews were set up as one interview per day and only conducted two days per week. The students emailed the researcher to indicate which of the four allocated sessions they could attend before the first interview. There were 3-6 participants per interview. Thirteen of these students are from Malaysia, one from Brunei and one from Singapore. Eight IM students spent their pre-clinical year $\left(1^{\text {st }}-3^{\text {rd }}\right.$ year $)$ in their home countries. Seven IM students did their preclinical study in New Zealand. All the students have studied at Christchurch School of Medicine for at least one semester.

This chapter reports on the themes that emerged from transcribing four focus group interviews. These themes are interconnected and act as building blocks to one another. It is possible that some quotes from the transcripts are suitable to more than one theme.

\section{Experiences and perceptions of libraries in comparison to their home countries}

These IM students have been studying in New Zealand between 1 to 5 years. Seven of these students spent three years at Dunedin School of Medicine before starting their clinical study $\left(4^{\text {th }}-6^{\text {th }}\right.$ year $)$ at Christchurch School of Medicine, whilst the other eight came to start their $4^{\text {th }}$ year at Christchurch Campus straight from the schools of medicine 
in their home countries. These IM students were asked to elaborate their perception and experience of the academic medical libraries they used during their pre-clinical year and their clinical year at Christchurch School of medicine.

The participants use the Canterbury Medical Library regularly for various reasons. Some students agree that they now come to the library more than they used to when they were in their home countries because of its conveniences for their study:

Over here I use the library heaps more than I did back home because back home we have more restriction like we need to wear a tie to go into the library and stuff. So if I wanted to study I'd just go back home why bother going to the library but here if I have time I do go to the library just to study or to return or borrow books something like that you know.

The students stress the need of information technologies in relation to accessing information online in order to do their study, library search and personal needs. The majority of students agree that having a student computer lab with the library is beneficial. They can satisfy their personal and educational requirement in one place. This is another reason that compels them to use the library more:

For myself because the computer lab is together with the library here. I would say I come to the library more often than I used to. So if there were two separate places like the library by itself and the computer lab by itself then I would say I wouldn't go the library that often. 
Where I came from the computer lab was next to the library but not in the library building like here. So I quite like the idea here.

The nature of medical teaching in the clinical training years $\left(4^{\text {th }}-6^{\text {th }}\right.$ year $)$, when students learn in a hospital setting and are required to be available for different training at clinical wards, also has an influence on how these students use the library:

It provides like a place to go in between classes you know or during break time. So I think when you know during pre-clinical phrase we just got lectures so after lectures we could go back home and did reading ourselves. But here we are expected to be here from 8 to 4 so we don't have classes in between at all or anything else in between so it's like a perfect place for us to sort of spend some time or free time to do some reading or check our mails or something like that.

While IM students positively see CML as a place for their study and leisure, the concerns about library space and size of the library collection especially textbooks are mentioned by all four groups:

This library is quite small compared to home. The Dunedin Medical Library is about the same size as here and accommodates more students. It was ok because after a while in a way I got used to it.

In term of physical space it's much smaller than home library but in term of services offered I guess there are not much different comparing to back home but I did notice that here we use more journals instead of books especially what's available in the library. There's not much books I guess for us to use. Compare to 
back home there are heaps of books especially textbooks. That's the difference I guess.

However, differences in pre-clinical and clinical teaching and medical education in a Western country like New Zealand might be the reason behind the selection and availability of textbooks in the library, as a few IM students suggest:

The way they teach medicine here is much more different from how they teach medicine at home. I think that's why we get the books available in the library here are different. I am not saying it's a bad thing that having less books here. It's just the difference that I can see.

The textbook collection here is a bit less than the one in Dunedin Medical Library but in a way I think the collection is sufficient and relevant to what we need and what we want to find information from. The other thing is that Dunedin Medical library of course usually where we spent our pre-clinical year there so that's when we need more medical textbooks whereas here although there are less medical textbooks but we're introduced to a wider range of the database on the internet. This is quite different from the year in Dunedin. In Dunedin we only use, at least for me, I only was introduced to Ovid Medline not other kind of evidence-based databases or resources. These online resources are relevant to our clinical study. Nowadays clinical studying emphasises quite a lot on the up-to-date and current information. Most of these are in journals which come out more often. Textbooks are not mentioned much anymore 
IM students from all four interview sessions stress their concern about numbers of copies of textbooks available, unavailability of non-study related materials, and library's lack of facilities such as self-checking machine, private and group study areas:

I think for myself more study area will be useful because at the moment it's quite limited there's only one big table on the $5^{\text {th }}$ floor for group, Maybe we can get rid of some print journals in the library to make more study area. More cubical, different couches and different kind of chairs will be a good idea.

Other type of book and newspaper. Non-textbook but still relevant to medicine, health science and scientific. Lighter reading material. I want to know why we don't have newspaper in the library. I never enter a library that doesn't have a newspaper and it doesn't cost too much.

In Dunedin Central Library not only they do have local newspapers but international as well. So it's quite cool. And is it too much to ask for a self-check out machine like we have in Dunedin.

\section{Awareness of library system and library services}

Nearly all the students mention that they use the library for studying, borrowing books, or accessing online resources. IM students were asked whether there are other library services that they use or not use and their knowledge of these services. Library orientation and instruction sessions are recalled by every group. Accessing electronic journals and databases was also mentioned by every student: 
I use journals a lot especially e-journals. Up To Date is really good even though it's not e-journals. It's very convenient because you can access it from anywhere.

When we got here we actually had our orientation week and then we had a special session on the library. The library session about introduce you to the library system and about how to use the library facilities and a little bit about EBM (Evidence Based Medicine) kind of stuff and how to do a library searches. International students come about two weeks before the term starts and have the orientation during those weeks.

During 5 weeks of the general practice attachment (also called GP run) all $4^{\text {th }}$ year students gain their clinical experience by working with different general practitioners in their practices. Fourth year students are divided into several small groups and each group has its turn for GP attachment at different times by one after another throughout the academic year. The students receive two sessions of 1.5 hour GP run training by CML reference librarian; sessions are on the first and second week of the attachment. The students are introduced to various significant databases i.e. Cochrane Library, Medline, and BMJ Learning. They learn how to search Medline, use search filter and limits for information needed for their real medical cases from their time spent at the GP practice, and how to use the bibliographic software program Endnote. This is the only library training medical students receive throughout their clinical years $\left(4^{\text {th }}-6^{\text {th }}\right.$ academic year). These training sessions are highly regarded and mentioned by all four groups of IM student participants: 
I think it's good for me like OVID is quite new to me so it just like a perfect opportunity for me to know that kind of stuff. Like an introduction of databases or database search and we had a session before GP run.

However, a small number of IM students had their GP run sessions later than others. They feel that they do not fully benefit from utilising these library skills in their clinical training:

I think that one for GP run is better to be done earlier in the year because I had my GP run near the end of the year so I only knew about the database at the end of the year. I think it will be better if everyone does it at the beginning of the year. I think it's a lot easier the database after you learnt how to use it

Even though these library sessions are instructed by reference librarians, more than half of IM students never heard about reference desk or reference services. While the role of the lending desk is well understood, none of the student participants can confidently describe the role of the reference desk:

To be honest I don't know what the other desk is for. I know it's in the middle but I don't know what they do.

Is it like an information desk? They help people searching library catalogue or something like that.

Nonetheless few students in each group received help from reference librarians in the past; either being approach by a reference librarian while they were looking for a book in 
the aisle or being referred to a reference librarian by a staff at the lending desk, and were very satisfied with the services given:

I remember one time I was looking for a textbook but I couldn't find it on the shelf and a librarian from that desk must see me so she came to help. She was very helpful.

Beside the uncertainty about the reference librarians' roles, the interviews reveal many other library services and resources such as inter-library loan, borrow direct, and past exam papers online are unknown or unused by these IM students:

I usually get the textbook from student reserve or I go straight to the book area and browse the shelves. I don't check online catalogue. If it's not on the shelf I just ask my friends. I don’t know that we can make request a request.

I think the issue is that students don't know about what services provided by the library. So they just approach the librarians only when they need something yet without knowing what kind of services they provide.

The students are glad to learn about these available services yet virtually everyone strongly goes against the proposed idea of a separate library instructions run solely for all IM students. They think that library services should be expansively advertised:

Personally I'm fine to stay with the rest of the class but I'm not sure about those students who come from IMU [Malaysian students who start in $4^{\text {th }}$ year] because they are new in the country everything will be new to them like the system of the 
library as well. Maybe they need more information about how to use the library catalogue and other stuff like that maybe more brochure more information. It's a good idea to have a choice to come back to have as an extra training adding on but maybe not be separated from normal group.

\section{Language and inter-cultural communication barriers}

Fewer than expected IM students state that they have difficulties in communication with librarians. All IM students must provide evidence of a satisfactory level of English language proficiency that meet the university's criteria before started their study. During the focus group interviews the majority of IM students are confident and comfortable in listening to and speaking English. In spite of this, three of these students are very shy and speak very quietly and only one student shares his anecdote of failing to find information and to get further help derived from a language barrier:

Sometimes I go up to the lending desk because I can't get the answer I want myself but I think probably it's because of me or my language is not that good and it happened once in the library I was asking about how to use the database or how to look for a book or something like that but I guess that the person at the desk can't understand my accent. She told me about how to use the computer but it was not what I wanted but I just said that "ok that's what I want" and just left and went to a friend. I guess that if you have more time with students you will understand their accents. 
Student participants from every group refer the librarians at CML as being friendly, approachable, and patient. They agree that the librarians are always available and willing to help. Yet when they are asked about their strategy to deal with difficulties using the library almost all participants try to figure things out themselves before asking a friend. Librarians are not IM students' first choice to ask for help:

I go to a friend and if I don't get the answer I just give up.

It's true because it's not like the database is not the only online system. If I can't access through the remote system I usually refer to a friend. Check if anyone can access the database. If they can't there might be something wrong with the whole system then I just wait and if it is just for myself that can't access the system then I will email or call an IT person.

I will look around for friends but if no one then I don't mind to walk up one floor from computer lab. I usually go to the lending desk. But if I can't access OVID I'll go to see an IT person rather than go to a librarian.

The IM students were then asked if their methods of dealing with these library-related issues were influenced by cultural differences. Their responses are that it depends on individuals and situations. They all agree that culture plays a part to some extent in how they deal with problem, but a person and generation characteristic are also important factors:

I don't think it has to do with culture it's more about we're born in this generation and you know everything is on the internet and we do Google search. I just want to comment about having some students who maybe shy or lack confident. They 
might not approach a librarian to ask for information. I think I do agree with that is has to do with culture. Asian students tend to be more shy compare to local students unless the ones that were brought up here with the kiwi culture. Typical Asian students also are more reserved and more shy. They are more afraid to ask and wouldn't dare approach a librarian. They would try by themselves and if it doesn't work then it's their problem not the librarian's problem. It's like the overpoliteness of Asian culture.

\section{Notion of medical academic library in medical education}

According to many, the ever increasing availability of information online may seem to reduce the need for library usage by medical students. The assumption of the medical academic library being obsolete is opposite to these IM students' opinions. Even though they consider themselves as computer literate and adaptable to Western academic and library system, they report that they still need library training and guidance from librarians:

I wouldn't say that the library is something that I couldn't study medicine if there was no library but it is something that hmm it's very useful to me to my study and it does help a lot in term of improving my knowledge in Medicine.

I think the library is compliment the whole process of study. I would say it is essential but it still depends on individuals. You know some people just can't study without the library but some might study in the library but some other time just they study outside the library. 
What I reckon is that the librarians play important role you know in our study area and even in medical career. When we need to find something and we don't know where we should start looking at. They are the perfect source you know that we can go to and talk to and ask information from.

We need people to guide us how to use the resources you know. Like this morning we had a special session with a librarian to show us how to use a database because there are a lot of resources out there we never knew before.

Many IM students hear about the benefit of using the library when they are in New Zealand from their friends and other senior IM students, usually of the same nationality. They regard it as useful advice and believe they will pass on the same advice to others: I'd recommend them to use the library it's much more useful than you expected because back home I'm not like use the library. Before I came here I never knew what librarian jobs are. I think they only make sure the books are well arranged and blah blah blah.

The librarians back home are not that friendly. In my opinion the librarians here are very friendly compare to the ones we have in my home country. One more thing that I personally give advice to other students who come here is, because I get asked about what kind of books are used here and what book they should bring, basically they can't bring a lots of books with them because their bag can only be 20 kilos. So just forget about the book and you got all the books here in the library so just borrow the books here. 


\section{CHAPTER 7}

\section{Discussion and Recommendations}

The findings from the transcripts of all four focus group interviews present parallel results to those in the literature discussed in the previous chapter. The issues of library usage and experience faced by the international medical (IM) students from Asian countries at Christchurch School of Medicine are comparable to Asian international students from other disciplines presented in many studies. The influence of their culture on their library experiences and usage of library services is slightly greater displayed in $4^{\text {th }}$ than $5^{\text {th }}$ year IM students from overseas, and again $4^{\text {th }}$ and $5^{\text {th }}$ year IM students from overseas demonstrate more difficulties in adjusting to New Zealand academic and library systems than the ones who spent their pre-clinical years in Dunedin.

These distinctive influences reflect the theories of cultural dimension by Hofstede (2001). Hofstede defines culture as the collective programming of the mind which distinguishes one group from another. Elements of culture manifest in an invisible form, which is internal value, and visible forms, which are external elements known as practices. Value is "a broad tendency to prefer certain states of affairs over others" and is at the core of culture. Values are revealed through practices which include rituals (collective activities), heroes (respectable persons), and symbols (words and gestures). According to Hofstede et al (2005), every group of people carries a set of common mental programs which comprise its culture. Differences between two organisational cultures are distinguished by their practices or common behaviours whereas differences between two national cultures are characterised by their values. Values and practices are acquired early in our lives and 
from our environment such as family, school and work. Consequently it is complex and problematical to change them later in our lives especially when facing another national culture. Hofstede's research presents the national culture in four dimensions. In his later writings he added the fifth dimension which is not suitable to use in this research as explained in chapter 3. These four dimensions are Power Distance (PDI), Uncertainty Individualism versus Collectivism (IDV), Masculinity versus Femininity (MAS), and Avoidance (UAI). The differences between the host culture of librarians and foreign cultures of IM students should be recognised, studied and managed by every librarian working for internationalised tertiary institutions.

In this chapter the four cultural dimensions theory of Hofstede is used to analyse how Asian culture visibly and invisibly influences IM students' behaviour in their academic library usage and experience of library services in the New Zealand tertiary environment.

\section{Experiences and perceptions of libraries in comparison to their home countries}

IM students start their clinical years by entering into a new academic environment. To be able to succeed at their clinical training they quickly face a transition period of adjustment to Western medical training where high self-reliance and innovation are encouraged (DaRosa et al, 1983; Shershneva et al, 2005). An academic medical library is considered as an important force for students' success in their study and a hub of resourceful information required in tertiary and clinical setting. However IM students, who have little or no experience in the Western educational system are not familiar with essay-based coursework and evidence-based (EBL) or problem-based (PBL) learning styles in their pre-clinical year. Their accustomed learning approaches of memorisation, 
observation and imitation $(\mathrm{Mu}, 2007)$ may help them thrive in pre-clinical years; however, the same strategies may not prepare them enough in the clinical year with less hours of lectures and more hours in hospital departments working with other health professionals and making decisions about patient care with the best available evidence (Hawthorne et al, 2004). Their common perception of the library as a place for textbooks and librarians as bookkeepers rather than as a place to research their study and as information providers needs to be addressed for a change. The finding from the focus group interviews confirms that the IM students' perception has changed. Their positive library experiences and new perception of library's role increase their usage of library services. Almost all IM students admit they used the library in their home country less and mainly to borrow and return textbooks. They also like to use the library for other purposes besides study, for example as a place to meet up with friends; a resting place during free time from training; and to use the computer lab for educational and personal reasons. Even though the IM students' positive experiences help increase the library usage, there are some concern about the library size and availability of textbooks, which show their expectations are not all met. The worry about the number of textbooks available for lending was mentioned by all four groups but predominantly by students from overseas medical schools. The findings show that $5^{\text {th }}$ year students from Dunedin have less concern about the availability of textbooks and their attitude toward textbooks dependability evidently changed to an acceptance of evidence-based learning style.

The explanation behind the increase of library usage and change in information seeking behaviour is likely clinical training style and lecturers' instructions. Clinical training's emphasis on evidence-based learning approaches requires medical students to use the 
most up-to-date information available. Textbooks contain reliable knowledge but are not frequently revised and updated. Moreover, the library does not always have the latest edition for all of them. Medical and science disciplinary fields prefer using journal articles to other sources (Whitmire, 2002). All $4^{\text {th }}$ medical students at Christchurch School of medicine are scheduled to have two sessions for an introduction to databases and database search training. They need to use these skills to complete their assignments. This practice is opposite to their pre-clinical year when lecturers give a precise instruction of what to do and read to pass their course.

The influence of uncertainty avoidance and power distance dimensions can be seen as the drivers behind IM students, especially those from overseas. IM students gave the reason that they did not frequently use the academic library in their home countries because of strict rule, such as dress code, and inconvenience; besides, they had no need to study in the library because they had their own textbooks to read at home. It is a clear example of power distance dimension in countries like Malaysia and Singapore or Brunei where teachers transfer their wisdom to students. The teacher is the centre of the educational process and dictates what and how students learn. Rote learning is preferred by teachers and textbooks, and teacher handouts are the main source of information and knowledge students need to learn. Therefore the library is not regarded as an integral part of the teaching and learning process. Students then do not see the library as a place to find information and knowledge. These IM students only used their home library because they needed to borrow the textbooks prescribed by their teachers. To get the exact books requested by teachers made these IM students feel secure and comfortable because strong uncertainty avoidance countries favour highly structured learning-teaching approaches. 
An exact instruction is preferable to students. These uncertainty avoidance and power distance dimensions are more strongly displayed in $4^{\text {th }}$ year IM students who recently arrived in New Zealand. They still would like to see more textbooks on the lending shelves and prefer clear instruction. They are in need of adjusting to a different cultural dimension of learning approaches. Other IM students who have been in New Zealand longer are already accustomed to the New Zealand learning approach of weak uncertainty avoidance and small power distance. These students are comfortable with studying independently and can be loosely instructed. Vague direction from teachers is no longer a worry because teachers only give guidance and students need to be self-reliant to find their own intellectual path. Moreover, the academic library is introduced as an integral part of medical teaching. IM students now realise that the library is a gateway to their knowledge and they can access the knowledge they need with librarians' help.

Medical librarians in academic setting must understand the cultural differences of this particular group of library users to better provide good experience and give IM students an insight into benefit of library services contributing to their academic success. From this research findings suggest medical librarians should coordinate with teaching staff and academic department to make sure the information need and requirement for clinical training is available in the library. Teaching staff can help increase the visibility of library services by stress the necessity of library skills in clinical training as well as in further career as health care providers. Librarians need to be patient and give IM students opportunity to grasp the new teaching approach where students are independent and find their own path of wisdom with guidance from teachers and helps from library. IM 
students need to perceive the academic medical library as an integral part of education not a separate entity in university like in their home countries.

\section{Awareness of library system and library services}

IM students from Dunedin campus have more experience and more familiar with New Zealand library system while groups of IM students from Malaysia, Singapore and Brunei are more concerned about the unfamiliar library system and services. However both groups require new set of information seeking skills in databases searching because they are introduced to Evidence-based learning-teaching style and clinical training in hospital environment. All 15 IM students evidently use lending service, such as borrowing, and returning, and attended their library tutorial; library orientation; and GP run training. Every IM students compliment the usefulness of library training prepared for the GP run. Few students with pre-clinical year from Dunedin point out that some library training and tutorials are already taught in Dunedin and some local peers missed those session. They did not mind to attend because these library sessions are scheduled in their programme and in case there are possibilities of newly added information. These IM students, who come from collective societies, prefer learning in a small group and participate more. Furthermore coming from strong uncertainty avoidance culture these students are more comfortable and enjoy the library session with a specific purpose and instruction in order to find the right answers like in GP run training. The similarity of this teaching approach of learning how to do in collectivist culture compares to the teaching in their home countries give these IM students a sense of confidence in their learning. Even some IM students mention the absence of their local peer and the repetition of information in 
difference basic library instruction they hesitate to miss out from being part of the group and interact with the peers. They have more concern about the collective duties of being accepted as a good team member and fear of rejection from the group specifically from the co-national ones. Missing from a class or complaint about repetition of content is undesirable behaviour because in collective society students belong to their family and attach to certain group and represent the family and group's virtues. These IM students avoid being seen or misinterpreted their action as disruption the group harmony or disrespect the wisdom given by teachers or in this case teaching librarians. The response from IM students to small group sessions with precise objectives and detailed lessons is positive and memorable. However after group session this group of IM students do not use reference services. There is only small number of IM students in the interviews tried to explain what they thought reference librarians did. Several IM students recalled that they were approached by reference librarians or referred to reference librarian by lending staff and had positive and successful transaction yet almost all students chose to go to the lending desk when they use the library. The uncertainty in the role of the reference librarians affects the use of specialised knowledge of reference services. These IM students use the lending desk services more frequently because the familiarity of the role of librarians in their home countries. In most Asian countries librarianship is not specialised profession. Librarians' roles are seen as clerical duties that locating, shelving and maintaining the physical side of the library and not in position or capability to offer sufficient advice or knowledge to help beyond locating beyond physical shelf and library wall (McSwiney, 2002; Wang, 2006). McSwiney (2002) suggests that perception of the reference librarian's role depends on the users' previous experiences. All 15 participants 
are regular users of lending desk services and undoubtedly comfortable with staff at lending desk because of they clearly perform the same duties as the librarians from IM student's home libraries. The IM students lack understanding of the reference service and automatically ignore the services. These IM students show strong uncertainty avoidance influence in the strategy to reduce their worry or fear by avoiding any ambiguity of reference librarian role without realising the potential advantage they may receive if venture into the unknown or doubtful part of library services. As the result the IM students suggest that there is a need for more detailed brochure and visible advertisement for library services that target exclusively to new IM students.

IM students participated in the focus group interview represent a special group of library users that have a specific preference of how the library services are delivered. The unfamiliar and unknown library services from their previous experience back home can prevent from reaping for the full benefit offered by academic medical librarians. The librarians must realise this specific way of learning and using services of IM students and adapt their teaching methods to suit requirement of student with different learning culture. By advertising clear and well structure service provided by specialised professional librarians and welcoming group sessions not just individual training to IM students should increase the visibility and utilisation of library services.

\section{Language and inter-cultural communication barriers}

IM students must meet University's criteria of language proficiency requirement. IM students' skills in reading and writing English are adequate because medical textbooks

and medical terms are dominantly written in English. However many IM students report 
that they lack English speaking skills before arriving in New Zealand. Writing, reading, listening and speaking skills in English are intensively used not only to pass their exam or understand their lecture, but also it is vital for them to be a capable communicator with patients and other health practitioners. English language proficiency does not pose any particular concern to this group of IM students. Only two out of the 15 IM students are quiet speakers, which make it hard to communicate at a fast pace. These student participants have a good command of English and pick up some New Zealand colloquialisms, particularly the IM students from Dunedin. From the researcher's observation, the English language itself is not the problem faced by IM students but rather the challenges of inter-cultural communication which can be crucial to their learning outcomes.

The way we communicate is influenced by culture. New Zealand English accent, colloquialisms, idioms, technical and library jargon can be very frustrating for many IM students. The example incident from one of the participant shows that his natural way of using his native language in database search in another language means that he may not get the search result he wanted. The same IM student also faced another challenge posed by what he thought was his accent. It could also be the way he asked the question that was misinterpreted by the librarians. Wang and Frank (2002) report that students from Asian countries tend to state that they understand even if they do not, or are uncertain about the answer. They respect an answer from the authority figure, which in this case is the librarian, and they do not want to lose face or make the librarian feel embarrassed either. Directness and assertiveness are not virtues in large power distance cultures with collective and feminist society. These IM students treat teachers or authority figures with 
respect. Arguments and aggression are not encouraged, especially in classroom. The IM students prefer to be seen as well behaved, modest, and not trouble makers or arrogant. IM students would choose not to have the help needed to find correct information, instead going an extra distance to seek it out themselves because they do not want to bother or disrupt the librarian (Liu and Winn, 2009; Xu and Davidhizar, 2009). In a situation such as this case, librarians are not always the first help IM students come to. Most IM students tend to ask their friends if they can not solve the problem themselves. This is the preference of typical collective culture where members of the group are interdependent; friendship is predetermined; and social networking is the primary source of information (Hofstede et al, 2005). IM students favour their friends from the similar background in particular to librarians.

The help or useful information or IM students learnt from librarians is usually shared with their friends who belong to their group. Another unique way of using language in collective society is the use of "we". The researcher noted the same use of "we" during the focus group interviews. When the question is directly asked about one person's experience, that person answered using "I" and sometimes changed this to "we". However these IM students commonly use "we" when they were questioned or simply expressed their personal opinion. Xu et al (2009) suggest that the "we" identity replaces the "I" identity in collectivism. The need of the group is chosen before your own.

Librarians need to carefully choose the method of communication with students from different cultures. IM students' communication pattern is influenced by their cultural background. Even though these students are competent English speakers, their thinking 
patterns are in their native language, where they have a different ways of expressing and displaying their reasoning (Zhang, 2006). Indirectiveness is a preferable style of verbal communication in Asian culture. Directiveness and assertiveness in communication is not a desirable quality and is viewed as rude and aggressive. As Xu et al (2009) explain, Asian students favour indirect and vague communication over direct and clear communication in order to maintain the group harmony and to "save face". Librarians are recommended to be patient and attentive to different forms of IM student communication. Mediums such as writing down on a piece of paper, showing a computer screen, and rephrasing back the question can alleviate the complicated transaction. Moreover, differences in accent, colloquialisms, idioms, technical and library jargon can create more problems to IM students than answering their question. These should be avoided and replaced with more simple words if suitable.

\section{Notion of medical academic library in medical education}

IM students in all four focus groups show their appreciation of the library presence in their medical training. They see library training, particularly database searching, as a useful and beneficial aspect of the library services. The library becomes more than just a place for textbooks once these IM students realise the necessity of the library in their clinical training. Their perception of the library has changed owing to various reasons. First IM students may grasp the model of Western educational structure where the library is highly regarded as an important part of the academic unit after they spend their time studying in New Zealand. The second the difference is the teaching methods of clinical training in New Zealand, where the small power distance and individualistic culture 
encourages students to be self-reliant and find their own intellectual paths. New Zealand teachers show students how to learn and support students to develop their own personal opinion using the best currently available evidences which can be used as evidence-based medicine. To be able to achieve these, IM students need to be equipped rather than hindered by library skill sets. DaRosa et al (1983) stress this point that the concept of responsible self-directed learning becomes extremely important to the medical student in the transition from the classroom to clinical training. 


\section{CHAPTER 8}

\section{Conclusion}

This research aimed to investigate how an Asian cultural background influences international medical students' use and experience of academic library services in New Zealand. The cultural differences among academic library users can still create barriers to international medical students from Asian countries - in this research Malaysia, Singapore, and Brunei - and give less chance for this group of students to fully benefit from library resources and services provided by specialised academic librarians.

Malaysia, Singapore, and Brunei are similar in cultural dimensions; however they are quite different from New Zealand in cultural dimensions. IM students' behaviour from these three countries in their library and information usage patterns reflects the typical characteristic of large power distance, collectivistic, feministic, and strong uncertainty avoidance culture. This special group of library users faces different difficulties using a medical library in their clinical year compared to their local peers. Many of these dominant issues are language and inter-cultural communication barrier, unfamiliar library system, different learning style and approach, and cultural differences.

The data from the interviews suggests that these students do come to appreciate the value of the library services available to their clinical practice as they progress in their clinical training years, from $4^{\text {th }}$ to $5^{\text {th }}$ year, and they develop more skills in using these services and sharing the knowledge with their IM students. However, this progress is slow when compared to local students, and it is ad-hoc: possibly a student or their peer-group will 
find useful information about library services, but other knowledge may elude them. Perhaps library training programmes could be expanded to encompass more information than it is assumed local students need. The students' expression of general satisfaction with library services, particularly as their understanding of these developed, suggests that a more concerted educational programme in this area would be beneficial. Certainly the cultural theories that have informed this study have been borne out by the data, with the Asian background students indicating ways of engaging with the library services that reflect Hofstede's views on cultural positions. Furthermore, the students' willingness to be interviewed, and how forthcoming they were in the interview process, indicates a growing perception of the importance of library services to their training and their careers, and a desire to share their experiences. Their reflections on these experiences that are presented in this research should go some small way to illuminating the experiences of students and other library users from foreign cultural backgrounds, which can improve the development of library services in an increasingly diverse and multi-cultural library and information environment. 


\section{Bibliography}

Ajayi, N. A. (2004). Library use and information-seeking behaviour of medical students. Anthropologist, 6(3), 209-213.

Adedibu, L. O., \& Adio, G. (1997). Information needs and information seeking patterns of medical students at Lautech, Ogbomoso. Aslib Proceedings, 49(9), 238-242.

Badke, W. (2002). International students: information literacy or academic literacy. Academic Exchange Quarterly, 6(4), 60-66.

Baron, S., \& Strout-Dapaz, A. (2001). Communicating with and empowering international students with a library skill set. Reference Services Review, 29(4), 314326.

Coates, J., Hiyama, K., \& Wellington, S. (2004). Patterns of difference: weaving threads to hold across the reference desk. Retrieved on October 23, 2009, from http://www.lianza.org.nz/library/files/store_017/Patterns_of_Difference_Coates.pdf

Conteh-Morgan, M.E. (2002). Connecting the dots: limited English proficiency, second language learning theories, and information literacy instruction. Journal of Academic Librarianship, 28(4), 191-196.

Curry, A., \& Copeman, D. (2005). Reference service to international students: a field stimulation research study. Journal of Academic Librarianship, 31(5), 409-420. 
DaRosa, D. A., Mast, T. A., Dawson-Saunders, B., Mazur, J., Ramsey, D. E., \& Folse, J. R. (1983). A study of the information-seeking skills of medical students and physician faculty. Journal of Medical Education, 58, 45-50.

Dahl, S. (2004). Intercultural Research: The Current State of Knowledge. Middlesex University Discussion Paper No. 26. Retrieved on May 3, 2009, from http://ssrn.com/abstract $=658202$

Deloitte for the Ministry of Education. (2008). The Experiences of International Students in New Zealand: report on the results of the national survey 2007. Retrieved on October 23, 2009, from http://www.educationcounts.govt.nz/publications/international/22971

DiMartino, D., \& Zoe, L.R. (2000). International students and the library: new tools, new users, and new instruction. In Jacobson, T.E., Williams, H.C. (Eds.), Teaching the New Library To Today's Users: Reaching International, Minority, Senior Citizens, Gay/Lesbian, First Generation, At-Risk, Graduate and Returning Students, and Distance Learners (pp. 17-43). New York: Neal-Shuman.

Drenth , P. J. D.(2004). Prologue: Culture's consequences revisited. In H. Vinken, J. Soeters, \& P. Ester (Eds.), Comparing cultures: dimensions of culture in a comparative perspective (pp. 1-4). Leiden ; Boston : Brill.

Du Mont, R. R., Buttlar, L., \& Caynon, W. (1994). Multiculturalism in libraries. Westport: Greenwood Press. 
Eskola, E. (1998). University students' information seeking behaviour in a changing learning environment - how are student's information needs, seeking and use affected by new teaching methods. Retrieved on October 23, 2009, from http://InformationR.net/ir/4-2/isic/eeskola.html.

Fitzjohn, J., Wilkinson, T., Gill, D., \& Mulder, R. (2003). The demographic characteristics of New Zealand medical students: the New Zealand Wellbeing, Intentions, Debt and Experiences (WIDE) Survey of Medical Students 2001 study. New Zealand Medical Journal, 116(1183), Retrieved on October 23, 2009, from http://www.nzma.org.nz/journal/116-1183/626/

Gibbs, A. (1997). Social research update: Focus groups. Retrieved on October 23, 2009, from http://sru.soc.surrey.ac.uk/SRU19.html

Gorman, G. E. \& Clayton, P. (2005). Qualitative research for the information professional: A practical handbook. London: Facet Publishing.

Hawthorne, L. A., Minas, I. H., \& Singh, B. (2004). A case study in the globalization of medical education: assisting overseas-born students at the University of Melbourne. Medical Teacher, 26( 2), 150-159.

Hofstede, G. H. (2001). Culture's consequences: comparing values, behaviors, institutions, and organizations across nations. Thousand Oaks, Calif.: Sage Publications.

Hofstede, G. H. \& Hofstede, G. J. (2005). Cultures and organisations: software of the mind. New York : McGraw-Hill. 
Jackson, P. A. (2005). Incoming international students and the library: a survey. Reference Services Review, 33(2), 197-209.

Klimidis, S., Minas, I. H., Stuart, G. W., \& Hayes, C. (1997). Cultural diversity in Australian medical education. Medical Education, 31, 58-66.

Lempp, H., \& Seale, C. (2006). Medical students' perceptions in relation to ethnicity and gender: a qualitative study. Medical Education, 35(6), Retrieved on October 23, 2009, from http://www.ncbi.nlm.nih.gov/pmc/articles/PMC1435754/

Liu, M., \& Redfern, B. (1997). Information seeking behaviour of multicultural students: a case study at San Jose State University. College \& Research Libraries, 58, 348-354.

Liu, G., \& Winn, D. (2009). Chinese graduate students and the Canadian academic library: a user study at the University of Winsor. Journal of Academic Librarianship, $35(6), 565-573$.

McSwiney, C. (2002). Cultural implications of a global context: the need for the reference librarian to ask again 'who is my client?'. Retrieved on October 23, 2009, from http://alia.org.au/publishing/alj/52.4/full.text/mcswiney.html

$\mathrm{Mu}, \mathrm{C}$. (2007). Marketing academic library resources and information services to international students from Asia. Reference Services Review, 35(4), 571-583.

New Zealand Ministry of Education (2003). Code of Practice for the Pastoral Care of International Students. Retrieved on October 23, 2009, from http://www.minedu.govt.nz/ /media/MinEdu/Files/EducationSectors/InternationalEdu cation/ProvidersOfIntEd/COPFullEnglish09.ashx 
New Zealand Ministry of Education (2008). International Student Enrolments in New Zealand 2001-2007. Retrieved on October 23, 2009, from http://www.educationcounts.govt.nz/_data/assets/pdf_file/0015/24711/International_ Student Enrolments in New Zealand 2001 - 2007.pdf

Pickard, A. J. (2007). Research methods in information. London: Facet Publishing.

Reece, G. J. (2005). Multiculturalism and library exhibits: sites of contested representation. Journal of Academic Librarianship, 31(4), 366-372.

Sackers, N., Secomb, B., \& Hulett, H. (2008). How well do you know your clients?: International students' preferences for learning about library services. Australian Academic \& Research Libraries, 39(1), 38-55.

Sackett, D. L., Rosenberg, W. M. C., Gray, J. A. M., Haynes, R. B., \& Richardson, W. S. (1996). Evidence Based Medicine: What It Is And What It Isn't: It's About Integrating Individual Clinical Expertise And The Best External Evidence. British Medical Journal, 312(7023), 71-72.

Shershneva, M. B., Slotnick, H. B., \& Mejicano, G. C. (2005). Learning to use learning resources during medical school and residency. Journal of the Medical Library Association, 93(2), 263-269.

Singham, M. (2006). Multiculturalism in New Zealand - the need for a new paradigm. Aotearoa Ethnic Network Journal, 1(1), 33-37.

Statistics New Zealand (2007). Ethnic groups in New Zealand. Retrieved on October 23, 2009, from http://www.stats.govt.nz/census/2006-census-data/quickstats-aboutculture-identity/quickstats-about-culture-and-identity.htm?page=para002Master 
Uchibayashi, T. (2000).Multiculturalism in public libraries \& cultural dimensions of quality service: how will theory of multiculturalism help public libraries improve customer service?. Unpublished Master of Library and Information Studies Research Project, School of Information Management, Victoria University of Wellington.

Wang, B. X. (2006). Academic library services to Chinese international students in New Zealand. Unpublished Master of Library and Information Studies Research Project, School of Information Management, Victoria University of Wellington.

Wang, J., \& Frank, D. G. (2002). Cross-cultural communication: Implications for effective information services in academic libraries. Libraries and the Academy, 2(2), 207-216.

Whitmire, E. (2002). Disciplinary differences and undergraduates' information-seeking behavior. Journal of the American Society for Information Science and Technology, 58(3), 631-638.

Woolf, K., Cave, J., Greenhalgh, T., \& Dacre, J. (2008). Ethnic stereotypes and the underachievement of UK medical students from ethnic minorities: qualitative study. British Medical Journal, 337, 611-615.

Xu, Y., \& Davidhizar, R. (2005). Intercultural communication in nursing education: When Asian students and American faculty converge. Journal of Nursing Education, 44(5), 209-215.

Zhang, L. (2006). Communication in academic libraries: an East Asian perspective. Reference Services Review, 34(1), 164-176. 


\section{Appendix 1:}

\section{Information Sheet}

\section{An investigation of cultural influence on academic library usage and experience of international medical students from Asian countries}

INFO 580: Research Project Researcher: Thanawadee (Anna) Pibulsilp

I am a Master of Library and Information Study student at Victoria University of Wellington. As part of my degree I am conducting a research project under the supervision of Brenda Chawner, Senior Lecturer in the School of Information Management. My project is a study of academic library services for international medical students from Asian countries. This project aims to reach a better understanding of how cultural characteristics affect library use and to identify ways in which academic libraries might improve their services to this group of students. It will involve focus group interviews with current international students at the Christchurch School of Medicine; the interviews will last approximately one hour, and will be recorded.

This project has a potential to benefit both international medical students and libraries. Students' behaviour and practice will be more fully understood, meaning that cultural barriers, which could prevent them from gaining information required for their study, may be reduced. The students should be better able to take advantage of library services to their full potential, and to improve their academic performance and educational experience in New Zealand. Academic libraries, at the same time, should be able to gain an insight into the extent to which culture influences international medical 
students' behaviour, and to utilise my research finding for improving the use and experiences of library services.

This project has been approved by the School of Information Management Human Ethics Committee.

Your participation is completely voluntary. All information or opinion participants provide will be kept strictly confidential, reported only in an aggregated or nonattributable form, and used for this project. A technical assistant will be present during the focus group interviews, and has signed a non-disclosure agreement saying that all discussions will be kept confidential. All participants are required to respect the confidentiality of other members of the same focus group and not to disclose or discuss anything said during the focus group interview once the interviews have been completed. A Summary of the results will be provided to all participants. Results will be published in the form of a research project deposited in the Victoria University of Wellington Library, and may be presented at conferences or published in professional journals. All material collected will be destroyed two years after the conclusion of the research.

Any questions about this project can be directed to the researcher or the supervisor:

\section{Researcher:}

Name: Thanawadee (Anna) Pibulsilp

Phone: (03) 364 0512; 0212504596

Email: pibulsthan@vuw.ac.nz or t.pibulsilp@otago.ac.nz

\section{Supervisor:}

Name: Brenda Chawner

Phone: (04) 4635780

Email: brenda.chawner@vuw.ac.nz 


\section{Appendix 2:}

\section{Student Consent Form}

\section{An investigation of cultural influence on academic library usage and experience of international medical students from Asian countries}

INFO 580: Research Project Researcher: Thanawadee (Anna) Pibulsilp

After reading the enclosed Information Sheet, please tick the following boxes and sign your name:

$\square \quad$ By signing this form I give my consent to being interviewed by Thanawadee (Anna) Pibulsilp and to having the information I provide used for this project.

$\square \quad$ I have read the attached Information Sheet, have understood the nature and purposes of this research project, and have been given the opportunity to seek further clarification or explanation.

$\square \quad$ I understand that any information or opinions I provide will be kept confidential, and reported only in an aggregated or non-attributable form, and will be destroyed two years after the conclusion of the research.

$\square \quad$ I understand that the results will be use for a research report that will be deposited in the Victoria University of Wellington Library, and may also be published in a journal or presented at a conference.

$\square \quad$ I give my permission for the interview to be audio recorded. 
$\square \quad$ I will not disclose or discuss anything said during the focus group interview once the interviews are complete.

If you would like feedback, please provide your email address here:

Please sign and date below:

Participant's Signature

Date

Researcher's Signature

Date 


\section{Appendix 3:}

\section{Technical Assistant Non-disclosure Agreement}

An investigation of cultural influence on academic library usage and experience of international medical students from Asian countries

INFO 580: Research Project Researcher: Thanawadee (Anna) Pibulsilp

I will be present at each focus group interview in charge of operating audio-recording for the research project. I agree to respect the confidentiality of all participants and not to disclose or discuss anything said during the focus group interview once the interviews are over.

By signing this consent form, you are indicating that you fully understand and agree with the above information.

Technical Assistant's signature

Date

Researcher's signature

Date 


\section{Appendix 4:}

\section{Interview Schedules}

\section{A. Participant's personal information}

Code:

1. Gender:
a. Male
b. Female
2. Age:
a. $18-21$
b. $22-25$
c. 26 or over

3. Country of origin:

\section{Level of Study:}
a. Fourth year student
b. Fifth year student

5. Years in New Zealand:
a. Less than 1
b. 1 to 2
c. 2 to 3
d. 3 to 4
e. 4 years or more

6. Years at University of Otago, Christchurch

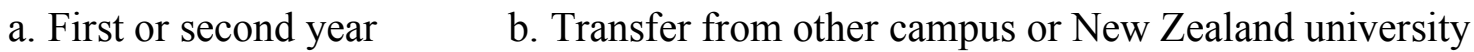




\section{B. Semi-Structured Interview Questions}

\section{Perceptions}

1. Can you tell me what role of library play in your study and medical training? Are they different from library in your own country?

2. What is your impression of the UOC library and its services (e.g. library setting, opening hours, resources, and facilities)?

3. How do these services match your expectations in comparison to those of University library in your country?

4. In your own words, what are the library lending service and reference services and in what way do you benefit from these services?

5. Can you give reasons why international students use or not use some services or resources that library offer?

\section{Experiences}

6. How did you use university libraries in your own country and how do you compare your experience or feeling to using university library in New Zealand?

7. What is your reason for a library visit? Can you think of any reason that may prevent you from using library and its services? Are these barrier cultural related?

8. Can you describe the library orientation/ database training/ tutorial you have attended? How do these training help you personally?

9. What are your experiences with locating materials, borrowing, renewing, and returning procedures of the library?

10. If you are unable to find something that you expect in the library what do you do and why? (e.g. Ask library staff at the circulation desk; ask library staff at the reference desk; ask classmates or friends; go to other libraries or go on the Internet)

11. Can you describe successful or unsuccessful stories in using library services or resources? Do you share with others when they have the same experience? 


\section{Suggestions}

12. What services would you like to see in the library?

13. Would you like the library to provide services specifically for international students, for example a separate training for international student only?

14. What do you think the library should do to promote less known services to international student?

15. In your opinion what the library can change to improve users' services and experience?

16. If you need to give an advice to international students about using the library what will you tell them? 
Thanawadee (Anna) Pibulsilp

INFO 580 Research Project

15,203 words 